\title{
Experiências do Design e Educação em duas pequenas ilhas no Golfo da Guiné
}

\author{
Experiences between Design and Education on two small islands in the Gulf of Guinea
}

\author{
JORDY, Eliane; DSC.; PUC-Rio \\ eliane.jordy@gmail.com \\ COUTO, Rita; DSc.; PUC-Rio \\ ricouto@puc-rio.br \\ PORTUGAL, Cristina; DSc.; PUC-Rio \\ crisportugal@gmail.com \\ VALLE, Carolina; PUC-Rio \\ carol53valle@gmail.com
}

\section{Resumo}

Este trabalho de caráter interdisciplinar entre design e educação apresenta reflexões que serviram como norteadoras na condução da pesquisa de ressignificação dos espaços educativos, em duas pequenas ilhas do Golfo da Guiné - São Tomé e Príncipe. Também apresenta alguns dos resultados alcançados durante o processo de pesquisa visando explorar possíveis contribuições ao espaço escolar, por ser o lugar, para além do espaço familiar, em que as crianças desenvolvem competências e habilidades cognitivas, colhem suas primeiras sensações, impressões e iniciam o processo de grandes transformações. A ressignificação dos espaços se constituiu como experiência piloto, servindo de inspiração para que outras escolas possam ser contempladas e fornece subsídios para melhorar a qualidade de escolas públicas em contextos semelhantes, podendo ser estendida também a escolas de regiões específicas do Brasil.

Palavras Chave: Design/Educação; Espaço escolar; São Tomé e Príncipe

\begin{abstract}
This interdisciplinary work between design and education presents ideas that served as guides in the conduction of the research of re-signification of the educational spaces in two small islands in the Gulf of Guinea - Sao Tome and Principe. It also presents some of the results achieved during the research process in order to explore possible contributions to the school space, because it is the place, beyond the family space, in which children develop cognitive skills and abilities, gather their first feelings, impressions and initiate the process of great transformations the re-signification of the spaces was constituted as pilot experiment. This pilot can serve as an inspiration for other schools can be met and provides grants to improve quality of public schools in similar contexts and may also be extended to schools in specific regions of Brazil.
\end{abstract}

Keywords: Design/Education; School space; Sao Tome and Principe. 


\section{Introdução}

Neste artigo as palavras nascem de uma experiência compartilhada entre o Design e a Educação. Alguns resultados e as reflexões apresentadas serviram como norteadoras na condução da pesquisa de ressignificação dos espaços educativos na República democrática de São Tomé e Príncipe, em África. Sendo parte integrante da Tese de Doutoramento de uma das autoras, e também, um dos produtos resultantes do projeto de pesquisa "Educação Infantil: uma proposta de ação sob o olhar do Design" ${ }^{1}$ desenvolvido no Programa de Pós-Graduação em Design da PUC-Rio.

O Design na Educação tem sido objeto de investigação sob variados enfoques e tem aberto muitas possibilidades de atuação para o designer, reafirmando a vocação interdisciplinar desta área de conhecimento. A cada novo estudo realizado no campo, o Design amplia seu sentido, alarga fronteiras e estende as suas possibilidades de atuação.

No que se refere ao espaço educacional, sua relevância se dá por ser o lugar onde as crianças passam a maior parte de seu tempo e, possivelmente, onde vivem importantes etapas que servirão de norte para suas vidas, considerando que crianças pequenas, oriundas de famílias de baixa renda, de camadas populares, não desfrutam do direito à infância, ao brincar, ao não-trabalho.

$\mathrm{Na}$ escola da infância, as crianças desenvolvem competências e habilidades cognitivas, sociais, colhem suas primeiras sensações, impressões e iniciam o processo de grandes transformações físicas, psicológicas, afetivas e sociais. Neste contexto, o espaço escolar torna-se ainda mais relevante por ser o primeiro lugar que habitamos, depois da casa familiar, um lugar impregnado de significados e valores, que se define por suas diferenças em relação a outros espaços ao proporcionar formas particulares de vivências, ao reunir coletivos de pessoas com fins educativos.

Neste sentido, refletir sobre o espaço implica também em avaliar caminhos percorridos por educadores; a interlocução que tiveram com designers, arquitetos e tantos outros profissionais que se dedicam a edificar o prédio escolar. Muitas marcas deixadas por esses profissionais, de modo favorável, ou não, determinam a maneira que espacialmente é habitada a escola, influindo na forma como as crianças se relacionam com outras pessoas, ao promover encontros, convivência, permitir a troca de conhecimento, definindo socialmente os usuários (atores sociais) do espaço, articulando, inclusive, quais possibilidades terão (JORDY, 2017, p.35).

Como instituição social, creches e pré-escolas são espaços de viver e devem ter compromissos com a qualidade de vida, potencializar a existência e oferecer a possibilidade de encontro com o mundo lúdico, além dos ambientes destinados a outras atividades educacionais. A brincadeira e os jogos infantis são modos de aprender que permitem que as crianças vivam experiências fundamentais que irão levar para a vida toda, como uma atividade importantíssima no processo de aprendizagem infantil, tão importantes quanto o ler e o escrever.

Apesar de já existirem inúmeras investigações sobre a qualidade do espaço escolar, ao refletirmos acerca de questões que relacionam o espaço ao desenvolvimento infantil, esse assunto

\footnotetext{
${ }^{1}$ Desenvolvido através de Acordo de Cooperação Técnica e Científica assinado no ano de 2012, entre a PUC-Rio, o UNICEF e o MECCC - Ministério de Educação, Cultura, Ciência e Comunicação da República Democrática de São Tomé e Príncipe, África.
} 
está longe de se esgotar. Principalmente porque são cada vez mais raras as escolas públicas que se mostram eficientes e adequadas à Educação Infantil - ao incluir espaços de viver, estimulantes para o brincar, para a experiência estética e contato com a natureza - além de oferecer ambientes destinados às atividades educacionais no estrito senso, já que o aprendizado não se dá apenas quando as crianças estão dentro de salas de aula.

\section{Design em Parceria}

A ação de projetar para contextos e sujeitos reais e distintos se realiza através da participação de áreas de conhecimento diferentes, para tanto, a prática de design voltada especificadamente para questões sociais necessita de uma relação de proximidade entre participantes e designers.

Neste estudo, o tratamento dado às questões relativas aos espaços de educação infantil teve por fio condutor o enfoque metodológico do Design em Parceria que se caracteriza como uma abordagem prática através da participação do grupo social envolvido (educadores, auxiliares, pedagogos e gestores).

Projetos de mediação no espaço coletivo comumente requerem a aceitação dos usuários, na apropriação desse novo espaço "qualificado, completado ou alterado pela relação que nele estabelece o indivíduo com outros indivíduos" (LIMA, 1989, p.14). O alcance desta apropriação se coloca como um desafio ao trabalho realizado, desafio que pode ser vencido através do uso de metodologias que possibilitam a participação de usuários na concepção projetual, como é o caso do Design em Parceria.

O trabalho de reforma das escolas nas ilhas foi pautado por inúmeras ações, que iniciaram com as visitas aos espaços educativos para levantamento de dados e necessidades. A elaboração da proposta buscou a validação pelos usuários dos elementos e etapas que compuseram o processo. Este tipo de enfoque tem na Pesquisa-Ação seu fio condutor, uma vez que se desenvolve a partir da contribuição dos vários sujeitos envolvidos no campo de investigação.

Ao analisar a aplicação dessa metodologia no âmbito educativo, percebe-se seu mérito em engajar as diferentes instâncias envolvidas. Especificamente no caso dos espaços da educação, considerando que cada escola tem um contexto próprio, peculiar e uma construção social que se constitui pelas práticas estabelecidas, os parâmetros para a ressignificação dos espaços educativos devem ser definidos a partir da identificação de necessidades que surgem da observação e integração com o grupo social.

Esse movimento de permanente ampliação de barreiras e limites permite que, na contemporaneidade, o Design possa ser estudado como estratégia para promover, estimular e construir novos cenários de desenvolvimento de diferentes atores sociais.

\section{São Tomé e Príncipe como campo de pesquisa}

A escolha de São Tomé e Príncipe como um campo de pesquisa se deu em função da possibilidade de realizar um projeto de cooperação que reunisse não apenas pesquisadores brasileiros, mas também pedagogos e educadores deste arquipélago, de pequena extensão territorial localizado na costa oeste do Continente Africano, em torno de algo que é coletivo, um bem de todos, como os espaços de educação.

O foco na Educação Infantil, onde o processo de formação das crianças se inicia, permitiu 
conhecer a realidade do sistema educativo são-tomense. Em que pese o fato de existirem nas ilhas carências de infraestruturas educativas, a realidade educacional aponta para um futuro promissor em função do envolvimento de seus educadores e dirigentes com o projeto de educação para crianças e jovens do país.

Figura 1 - Mapas com detalhe da localização de São Tomé e Príncipe

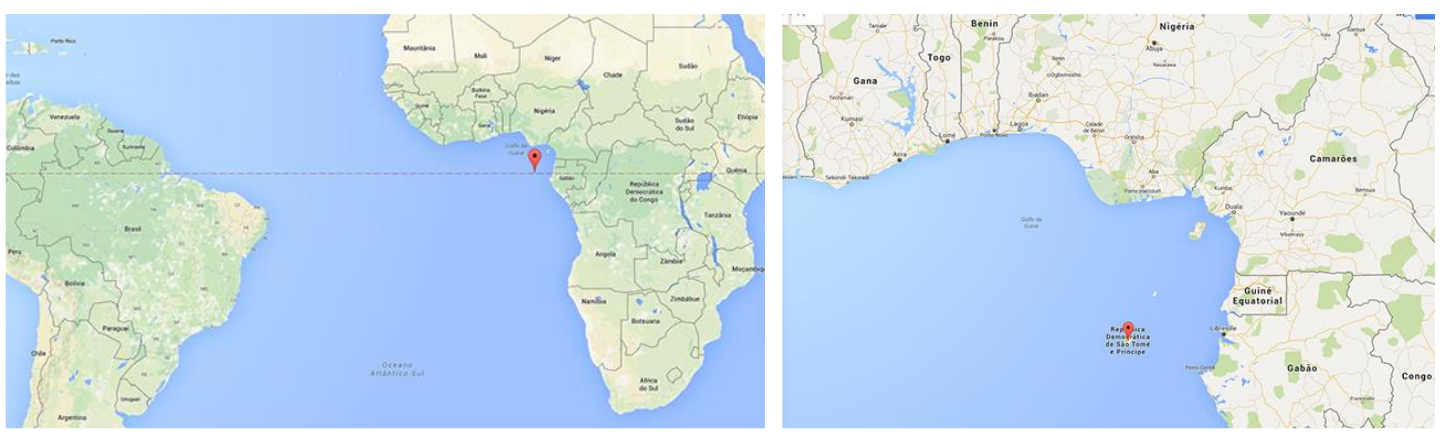

Fonte: Google Maps

Estando lado a lado no Atlântico - São Tomé e Príncipe e Brasil - ambos estão a mercê de uma natureza esplendida, inspirados pela terra, águas e árvores. Falamos a mesma língua, fomos colônia de Portugal, enfrentamos as adversidades com fôlego e resistência, temos desafios similares de desenvolvimento, além disso, muitas questões socioeconômicas que afligem o continente africano são igualmente enfrentadas no Brasil. Como afirma o escritor moçambicano Mia Couto (2005), "o oceano não separa aquilo que a cultura e história fizeram vizinho" (COUTO, 2005, p. 105).

Mobilizada por essas questões, o projeto de ressignificação dos espaços de pré-escolas trouxe, entre outros aspectos, a tarefa de verificação das condições envolvidas; as restrições de recurso e material disponível abrangendo também as diversidades existentes entre os ambientes de educação formal e informal. Referimo-nos não somente às condições sociais, históricas, econômicas e ambientais, como também às poéticas e culturas próprias do espaço insular, dado ao fato de que através do viés cultural se permite conhecer a identidade de um país.

\subsection{As viagens e missões}

Dada à distância geográfica de STP, os encontros presenciais em São Tomé e Príncipe ocorreram ao longo dos anos de 2013, 2014, 2015, 2016, possibilitando um estreitamento de laços com os educadores, auxiliares e dirigentes de diversas escolas dirigidas pelo Ministério da Educação, Cultura e Ciência de São Tomé e Príncipe.

Uma das mais recentes missões ${ }^{2}$ se constituiu em uma imersão de quinze dias, a convite da Universidade São Tomé e Príncipe e do Instituto Superior de Educação e Comunicação - ISEC, a partir de uma demanda dos educadores.

Em cada missão era proposta uma agenda de trabalho visando o atendimento dos objetivos e ações. No entanto, ao chegar ao campo a programação podia ser revista e adaptada em função das necessidades, demandas locais, e também, em função das características das próprias escolas.

\footnotetext{
2 julho de 2017
} 
Figura 2 - Imersão realizada em São Tomé
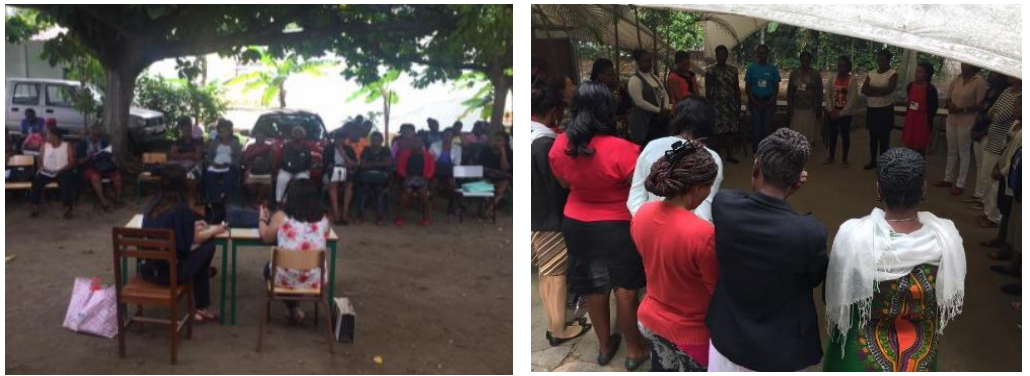

Fonte: As autoras

Figura 3 - Sala de aula em que foi realizada a imersão em São Tomé

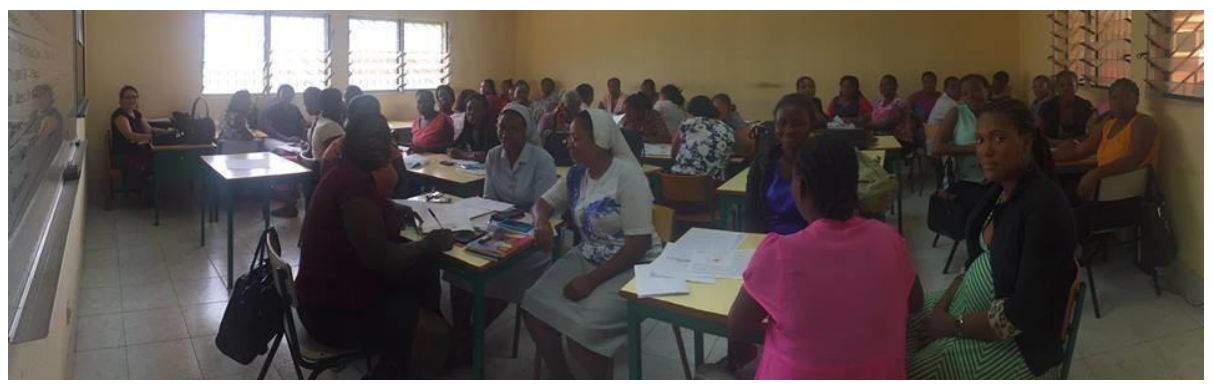

Fonte: As autoras

\section{Visão Geral do Método}

Para aproximação do objeto investigado a pesquisa teve natureza exploratória, tendo sido adotado um viés qualitativo. $O$ objeto da pesquisa foi elaborado simultaneamente ao avanço do movimento do trabalho de ressignificação das edificações escolares.

O ingresso no campo de pesquisa refinou uma postura investigativa diante do objeto de estudo contribuindo para a formulação da metodologia sob alguns ângulos. A vivência do cotidiano escolar clarificou a compreensão de que as práticas educativas, projetos e métodos pedagógicos demandam constante atualização dos espaços para que possam abrigar adequadamente as atividades de ensino (JORDY, 2018, p. 87).

As escolas Primeiro de Maio, Boa Entrada e Monte Café foram os primeiros espaços requalificados visando à melhoria do ambiente escolar público existente. 


\section{Artigo Completo}

Figura 4 - As escolas Primeiro de Maio, Boa Entrada e Monte Café
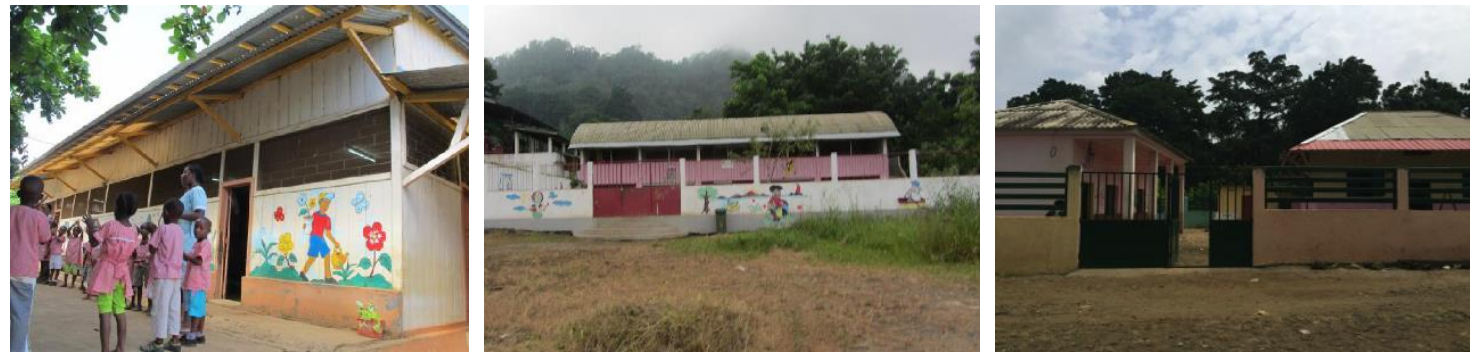

Fonte: As autoras

Foi realizado um inventário das configurações espaciais das escolas que seriam ressignificadas. A intenção foi de estabelecer relações entre os padrões de configuração encontrados e as finalidades educativas das instituições de forma a contribuir para o estabelecimento dos serviços na educação de crianças pequenas. Todo esse levantamento se deu em consonância com pesquisa relacionada à aprendizagem e desenvolvimento infantil, especificadamente de crianças entre 3 a 5 anos de idade.

Na sequência foram realizadas análise e interpretação dos dados coletados apontando os itens a serem projetados e os materiais construtivos adequados ao projeto - trabalhando de acordo com a cultura - dando usos adequados aos materiais e recursos naturais disponíveis, evitando descarte de resíduos que pudessem causar danos ao meio ambiente, destruição dos ecossistemas e a diminuição dos recursos naturais tão nobres nas ilhas.

Além disso, foi identificado o que se encontrava em bom estado de conservação nas edificações escolares e, portanto, seria mantido no projeto para não onerar os custos das obras. Em acordo com as limitações existentes no contexto socioeconômico sendo observadas as devidas proporções de recurso e de espaço disponível, assim como, o apelo ecológico e sustentável.

A ressignificação dos espaços da escola teria que lidar com o dinamismo próprio do cotidiano escolar, o que acabou por trazer complexidade ao projeto. Kowaltowski (2012), diz que essa complexidade é inerente ao processo, já que projetamos para um futuro ainda desconhecido.

A complexidade também se apresenta pelos usuários diversos que a escola abriga: alunos de idades variadas e em etapas de desenvolvimento diferentes, professores, funcionários, pais e membros da comunidade que frequentam a escola. Cada ano entram novos integrantes, que são desconhecidos e que também desconhecem a escola. Cada ano também, usuários deixam de frequentar a escola, porque cresceram e se formaram para enfrentarem novas etapas de vida (KOWALTOWSKI et al., 2012).

Desde o início do projeto havia, a intenção de contar com mão de obra local, seja a voluntária (no caso dos pais, moradores e amigos da escola, pessoas que mais conhecem os problemas de cada localidade), quanto prestadores de serviços, visando trazer benefícios de empoderamento social e econômico para os envolvidos, procurando criar condições para que as atividades pudessem crescer qualitativamente, economicamente e em termos humanos. No entanto, isso nem sempre foi possível, pois, segundo o próprio responsável pelas obras, poucos pais hoje têm disponibilidade de tempo, já que precisam trabalhar dobrado para prover o sustento de sua família. Outro fator que pesava era a ausência de um coordenador, alguém que promovesse a ação de forma inspiradora, incentivando, orientando e oferecendo a sua experiência, mas também sabendo escutar, trocar e se relacionar. 
O emprego das capacidades do Design na construção dos espaços da escola incluiu, também, verificar a forma como os materiais estão organizados, a qualidade e adequação dos mesmos dentro do projeto educativo. Devido ao contexto insular de São Tomé e Príncipe, foi fundamental, com base nas ideias de Moraes (2002, p.13), "promover o alcance de padrões mínimos de funcionamento" dos espaços de pré-escola. Nesse sentido, o processo de levantamento de dados previu a exploração inteligente do uso da luz - otimizando a luz natural, também porque muitas localidades ainda não têm luz elétrica, como era o caso da Escola de Monte Café. Como o clima nas ilhas é quente e úmido, foi importante também dotar ao máximo a estratégia de ventilação natural e cruzada, como forma de amenização climática.

Para ilustrar o trabalho desenvolvido, apresentamos algumas imagens da Escola Primeiro de Maio; Creche Escola Monte Café e Boa Entrada com resultados do processo de reforma das escolas, entremeando com falas das entrevistas semiestruturadas de educadores, gestores e o parceiro responsável pelas obras, além de algumas reflexões que serviram como norteadoras na condução da ressignificação dos espaços. Optamos pela utilização da entrevista semiestruturada como recurso metodológico com o intuito de captar a intersubjetividade dos sujeitos na materialidade de suas falas e no discurso que as organizam.

A Escola Monte Café situada na localidade da antiga sede da Sociedade Agrícola de Terras de Monte Café, na região de Mé-zóchi. Por ocasião da pesquisa, Maria Alice Paquete de Sousa era a gestora responsável pela Creche Escola.

A Escola Primeiro de Maio, localizada no distrito de Água Grande, Bairro da liberdade. Helder da Luz de Sousa Pontes é o gestor responsável. Ele trabalha na escola há seis anos.

A Escola Boa Entrada está localizada no distrito de Lobata. Malier Georgina Neto de Ceita Ramos dos Santos é a gestora responsável pelo Jardim de infância.

Figura 5 - Mapa com a localização das Ilhas de São Tomé e Príncipe e das 3 escolas ressignificada

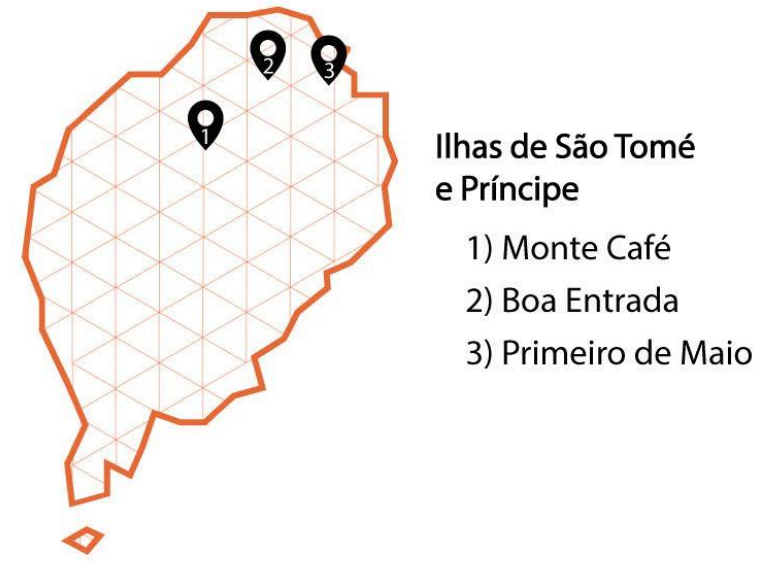

Fonte: As autoras

As três escolas reformadas se encontram situadas em regiões com características distintas, com áreas de vulnerabilidade que haviam de ser levadas em consideração diante do desenvolvimento de um projeto próprio, capaz de atender as particularidades de cada espaço escolar. Não foi recomendável, portanto, a simples replicação de práticas, pois o que seria bom para 
uma localidade, poderia não fazer nenhum sentido em outra.

Para desenvolvimento do projeto, a metodologia do design em parceria buscou o estreitamento dos laços com o grupo de educadores, gestores das escolas, pais, parceiros de trabalho ${ }^{3}$ e inclusive a comunidade local, como grupo social, apontando necessidades e criando subsídios para o conceito a ser adotado na ressignificação das escolas.

O investimento em criação de vínculos com a comunidade é um dos pressupostos do design em parceria. O estreitamento do vínculo é importante já que a instituição de ensino funciona como um polo que dissemina e irradia conhecimento, podendo, portanto, influenciar todo o seu entorno.

Sobre a participação ativa da comunidade local (pais, moradores do entorno), alguns educadores comentaram:

Há quatro anos quando cheguei em Monte Café era tudo de perna para o ar na escola. Os pais é que fizeram a pintura. Agora a vida está difícil, os pais são camponeses, agricultores e já chegam cansados em casa.

(Maria Alice Paquete de Sousa)

Essa área aqui é toda agrícola. Quando o branco foi embora ele deu o pedaço de terra, mas a pessoa tem a terra, mas não trabalha o terreno, fica sem receber nada. Só quando há festas comemorativas - natal, carnaval, festa de família, os pais participam com o lanche, com alguma contribuição. Com máscaras e sainha para o carnaval.

(Malier Georgina Neto de Ceita Ramos dos Santos)

A gente sabe da necessidade de envolver a população nas decisões. Mas nem sempre isso é possível.

(Tiago Coucelo)

As obras realizadas nas três escolas foram de substituição de telhados, construção de muros, cercas; colocação de revestimento cerâmico; reconstrução e pintura geral das edificações; requalificação estrutural; recuperação de coberturas; melhorias nos sistemas hidráulico e sanitário; instalação de rede elétrica e reforma das casas de banho. Além disso, as hortas foram refeitas, os brinquedos restaurados e o espaço externo, ao ser ampliado, ganhou novos brinquedos.

$\mathrm{Na}$ medida em que a parceria foi se instaurando, desencadeada pelo envolvimento no processo de design, após cada conquista vivenciada nas etapas de trabalho, foi possível revermos o alcance da proposta. Para Fontoura (2011), o Design determina a melhor opção de projeto quando otimiza as soluções dos problemas apresentados no dia-a-dia, dentro de determinadas circunstâncias.

Alguns serviços contaram com o apoio da comunidade e dos pais das crianças, como o caso da reforma dos móveis das salas de aula.

${ }^{3}$ Unicef e Ministério da Educação da República Democrática de São Tomé e Príncipe. 
Figura 6 - Reforma dos móveis por pais e voluntários
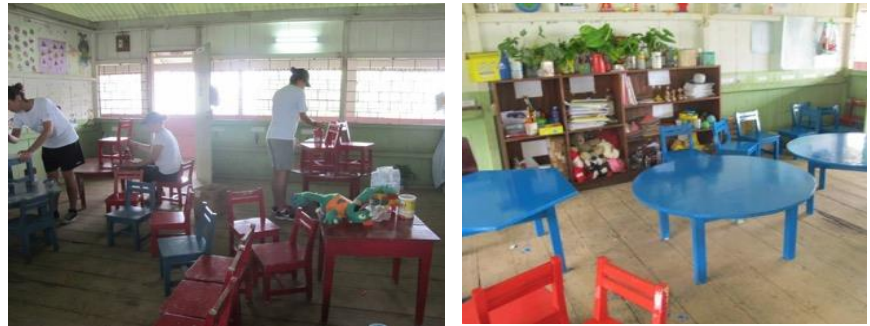

Fonte: As autoras

Como a maioria das escolas estão situadas em áreas agrícolas, é habitual a criação de uma horta, mesmo que seja apenas para consumo. Por isso, foi bem aceita a ideia de reforma dos canteiros para constituição de hortas pedagógicas, dessa forma as crianças aprendem a cultivar hortaliças, e a atividade proporciona às crianças conhecerem e valorizarem as práticas campesinas.

Os educadores apoiaram a ideia de reforma das hortas e estimularam a atividade com as crianças:

Todo mundo gosta de mexer com a horta. As crianças de 4 a 5 anos tiram o mato que fica em volta da cenoura e ajudam a semear também [...]. No caminho entre os canteiros as crianças colocam o capim arrancado. Há uma tradição de agricultura em Monte Café.

(Maria Alice Paquete de Sousa)

Quem fez os primeiros canteiros da escola foram três pais e algumas crianças. Um senhor, camponês da região, indicou o melhor lugar para a horta, aproveitando a queda da água que desce na bica principal foram feitas canteiros que são irrigados com a água que desce \{...\}. As redes que tiraram do cercado do muro eu queria ter aproveitado para fazer uma cerca para a horta [...]. Eu queria canteiros com formas de triângulo, circulo, retângulo e quadrado. Cada faixa etária seria responsável por um canteiro. Mas isso ainda não foi feito.

(Malier Georgina Neto de Ceita Ramos dos Santos)

Figura 7 - Ressignificação da horta
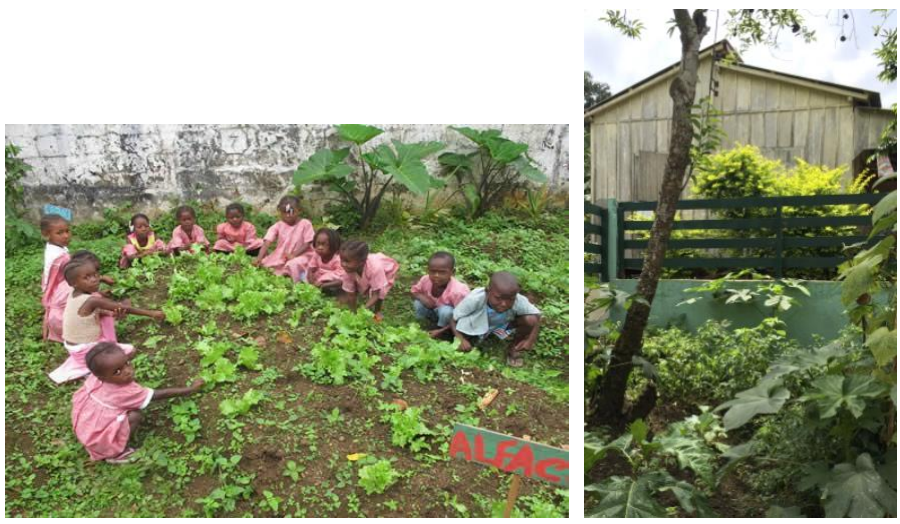

Fonte: As autoras

O cercamento das escolas foi uma medida julgada necessária para a segurança de todos. Da mesma forma, a construção da cerca da horta de Monte Café, visava criar uma fronteira na área 
exterior da horta de forma a protege-la. O material escolhido foi o bambu por ser uma alternativa manual, que necessita apenas do trabalho de corte e amarrações para seu manuseio, além de abundante na região.

A reforma dos portões e a construção do novo muro das escolas oportunizou uma entrada convidativa, e os espaços passaram a ter uma identidade própria ao distinguir a escola, dentro da comunidade. O oferecimento de um ambiente de transição mais amplo, durante a entrada e saída da escola, permitiu a acessibilidade da população escolar.

A Escola de Boa Entrada passou a contar com um portão para carros. Isso possibilitou a recepção de materiais da despensa e acolhimento de profissionais para serviços de apoio. É importante destacar que a qualidade no cuidado das crianças depende inclusive de um apoio logístico, ao oferecer condições para o bom funcionamento escolar. Nesse sentido, o portão com possibilidade de entrada de carros foi bem recebido na escola, segundo depoimento da gestora:

Quando eu comecei a trabalhar aqui entrava até cabra no terreno. As pessoas furavam a rede 4 e entravam na escola, as crianças 'andavam no baloiço ${ }^{5}$. Crianças maiores partiram o cabo do baloiço andando. Com o portão tudo isso acabou[...]. Foi muito bom a escola passar a ter um portão para o carro entrar. Assim quando chegam os materiais da cozinha a comunidade não precisa ver o que é. Antes eles me pediam comida. Pediam para trocar madeira por arroz, caneca de feijão por uma limpeza do capim da entrada. Agora já não acontece mais.

(Malier Georgina Neto de Ceita Ramos dos Santos, gestora da Escola Boa Entrada)

Figura 8 - Os portões e os muros foram reformados nas três escolas

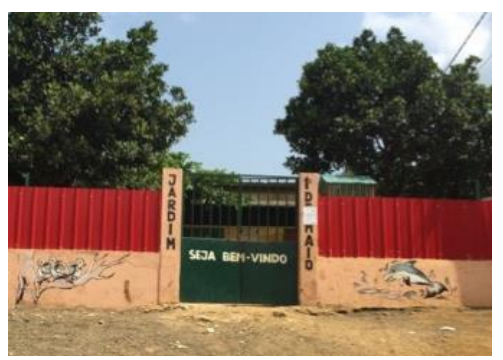

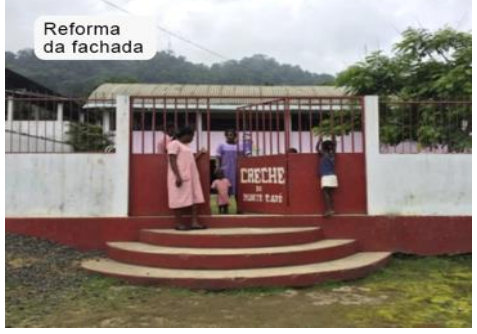

Fonte: As autoras

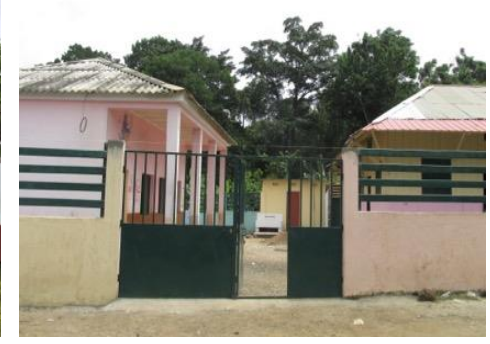

Uma das necessidades da Escola Primeiro de Maio era a melhoria das condições do telhado. Por ocasião da reforma, o gestor pediu para ser feita uma ampliação do telhado, de forma que pudesse unir o prédio da escola ao das casas de banho. Isso originou a criação de um novo espaço, anteriormente utilizado apenas como passagem.

\footnotetext{
${ }^{4} \mathrm{~A}$ escola era cercada por uma tela aramada, também chamada de rede, em Stp.

${ }^{5}$ Como são chamados os balanços para as crianças brincarem.
} 
Figura 9 - Requalificação do telhado da Escola Primeiro de Maio
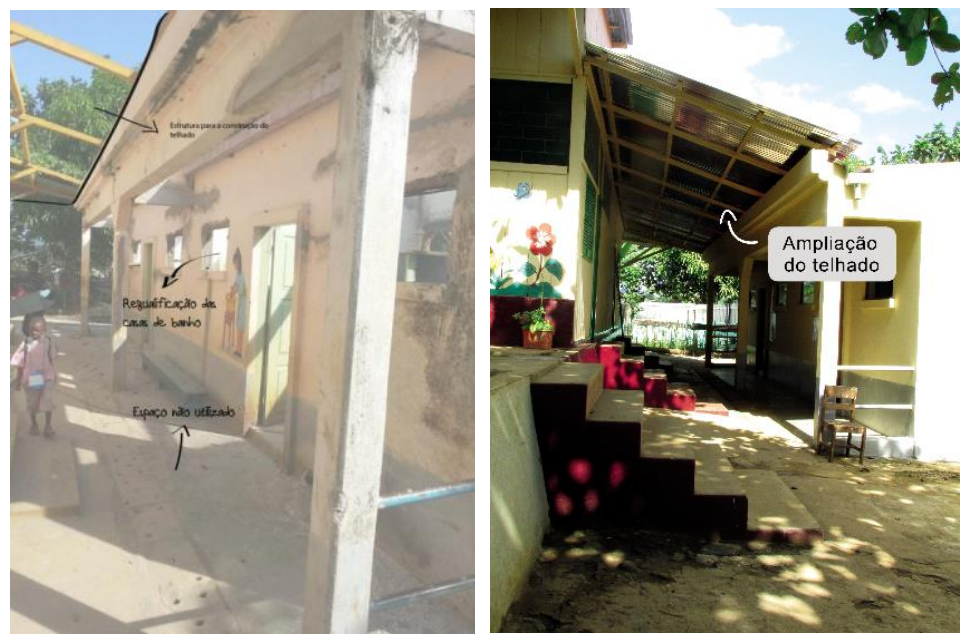

Fonte: As autoras

Em conversa com os educadores, foi esboçado o desejo de que a escola tivesse um espaço destinado para atividades de leitura com as crianças. O novo espaço, que antes seria apenas uma passagem para as casas de banho, virou um lugar interessante com a criação de um espaço de leitura. Foi necessária a verificação das condições do espaço para suportar livros, já que as paredes da escola são de madeira. Alguns livros ${ }^{6}$, as prateleiras e os suportes vieram do Brasil.

Visando a apropriação das crianças, medimos o alcance de suas mãos e instalamos as prateleiras de modo que elas mesmas pudessem ter acesso aos livros, gibis etc. Colocamos alguns exemplares dispostos em mesas baixas e em caixas para que as crianças pequenas também pudessem ser incluídas na sala de leitura.

Figura 10 - Infográfico com o passo-a-passo da construção do espaço de leitura

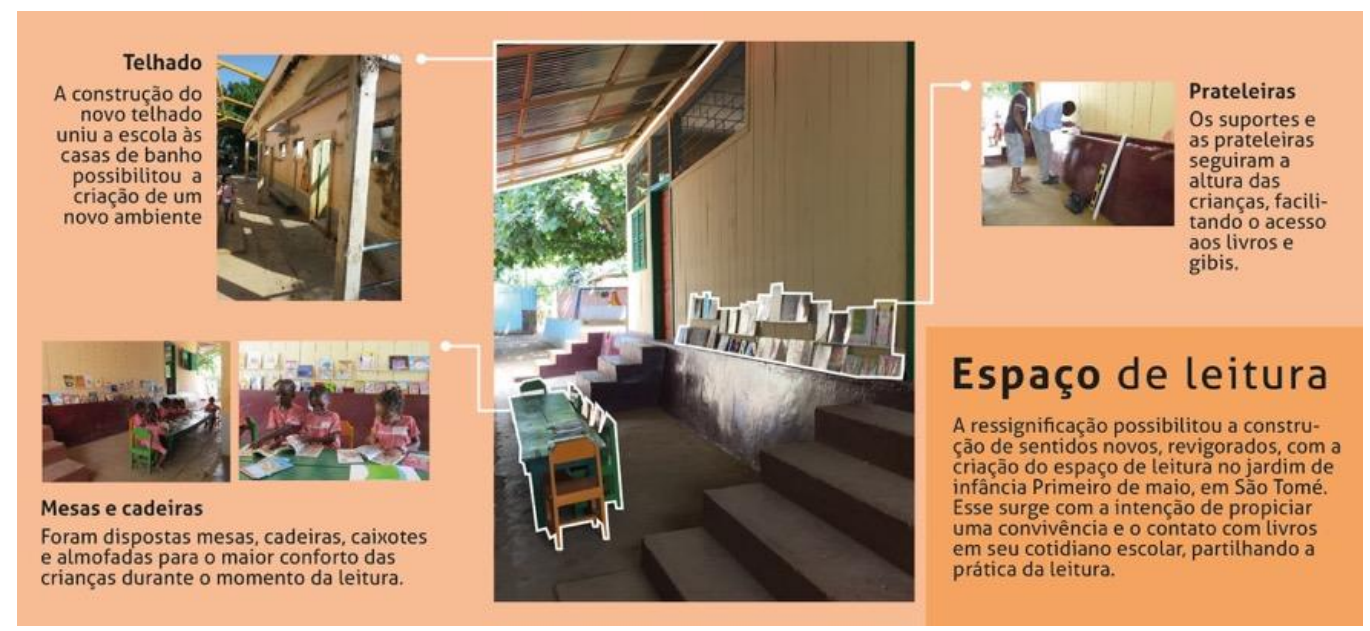

Fonte: As autoras

\footnotetext{
${ }^{6}$ Recebemos doação da Biblioteca comunitária Atelier das Palavras, localizada na Mangueira. E da Cátedra Unesco de Leitura PUCRio para levar para São Tomé e Príncipe.
} 
Posteriormente iniciamos a organização do espaço de leitura em Monte Café e na escola de Boa Entrada, igualmente em ambientes adaptados permitindo a acessibilidade das crianças aos livros. O princípio da organização dos espaços de leitura foi o de permitir que as crianças pudessem usufruir do ambiente.

Figura 11 - Exemplo de imagem
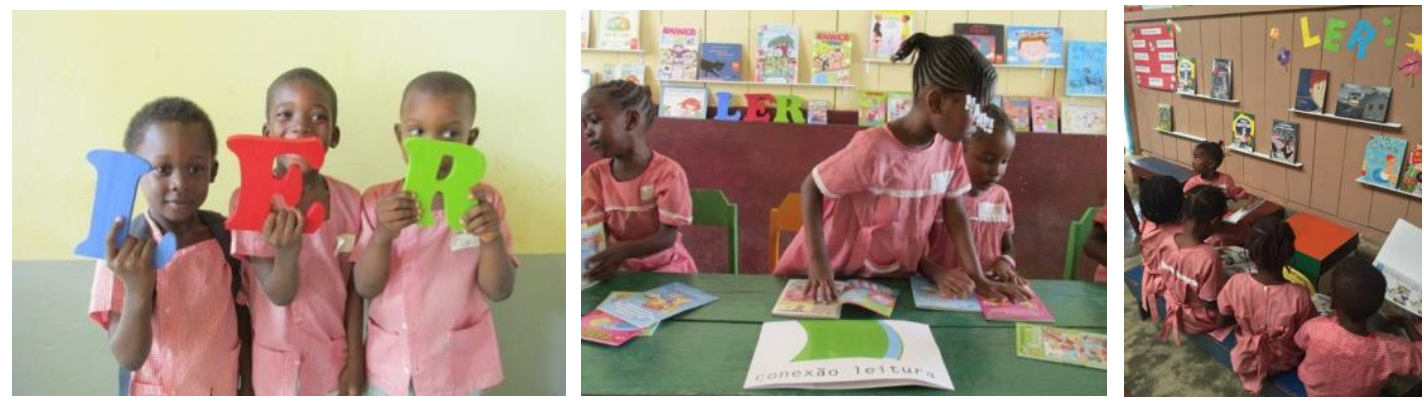

Fonte: As autoras

A estrutura sanitária das escolas foi reabilitada, as casas de banho receberam vasos turcos, onde as crianças usam a posição de cócoras para evacuar, semelhante ao hábito de defecar ao ar livre. Chuveiros foram instalados e lavatórios coletivos para as mãos foram construídos.

Figura 12 - Instalação de pia coletiva para lavagem de mãos e reforma das casas de banho
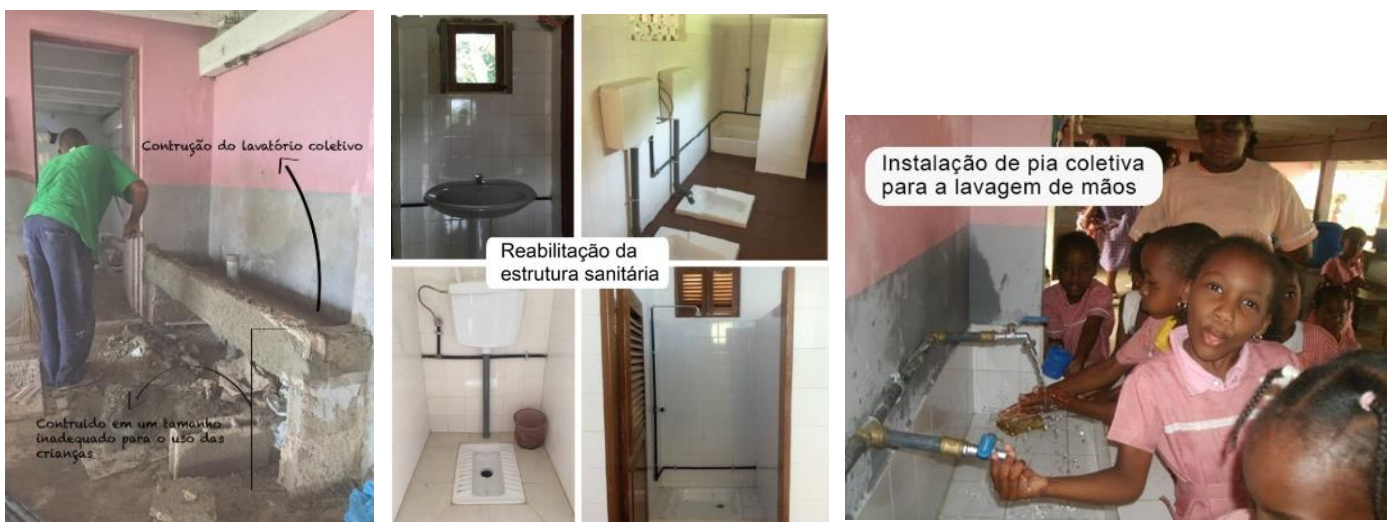

Fonte: As autoras

Figura 13 - Pintura do espaço interior e exterior e colocação de novas janelas
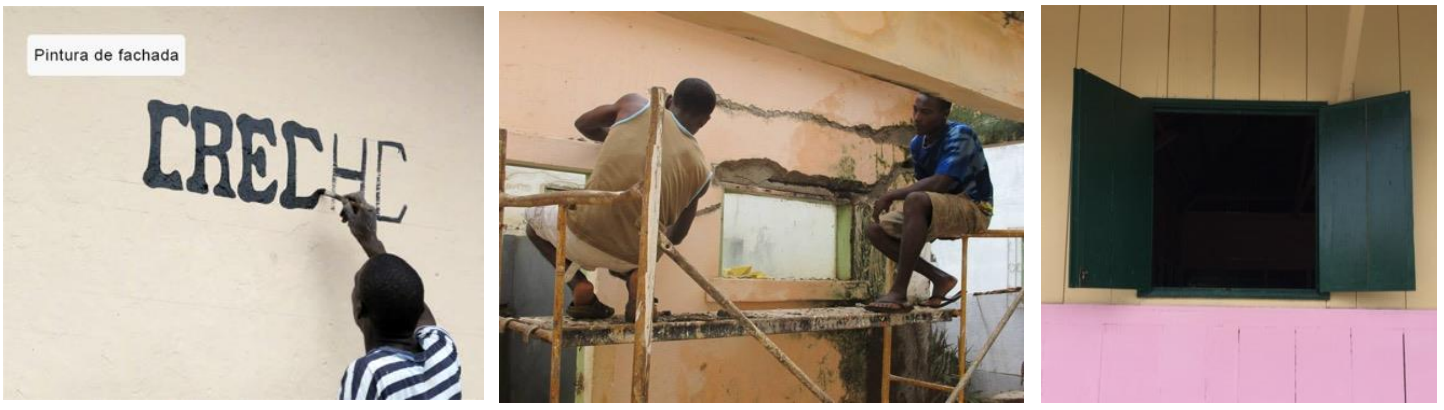

Fonte: ONGD Helpo 
Foi apontada a ausência de espaços específicos para atividades lúdicas e brincadeiras ao ar livre nas escolas de São Tomé. Visando sanar algumas carências, inclusive de oferecimento de materiais educativos, construímos murais de azulejo nas escolas.

Figura 14 - Painéis de azulejos instalados nos muros para atividades com tintas
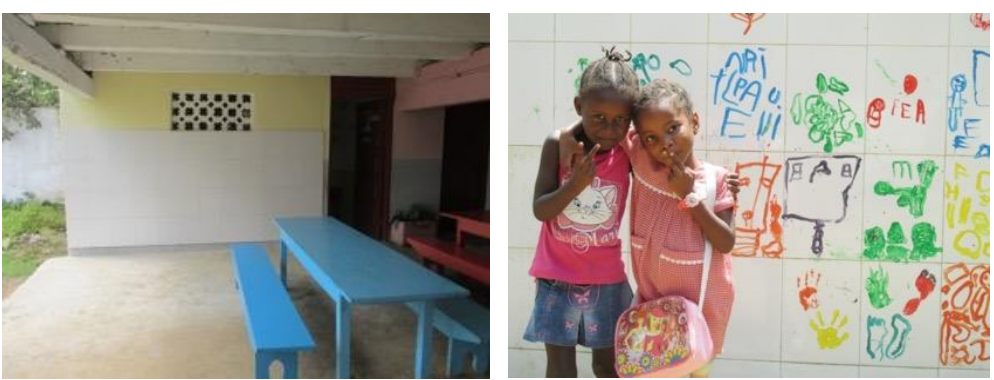

Fonte: As autoras

Figura 15 - Reforma dos brinquedos
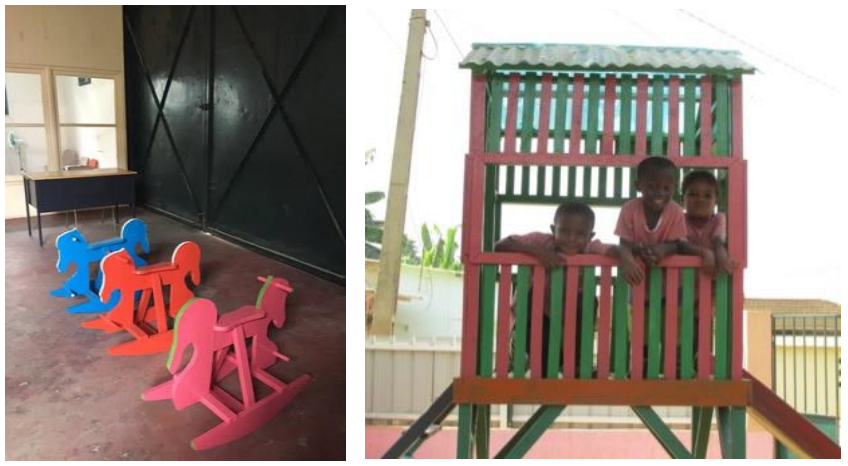

Fonte: As autoras

Figura 16 - Crianças na área exterior ressignificada

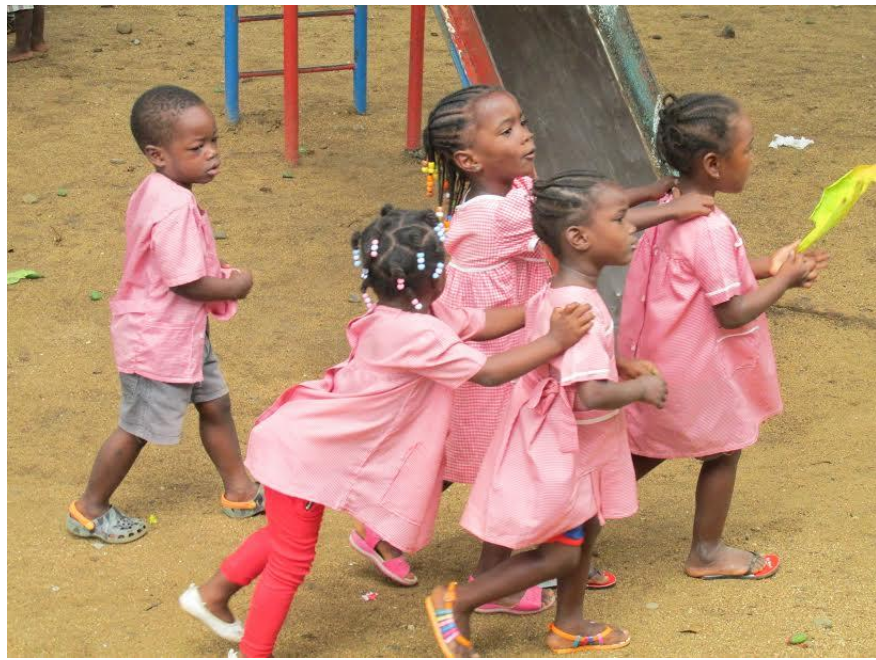

Fonte: As autoras 


\section{Considerações Finais}

A partir das questões acima contempladas, foi possível pensar de modo mais amplo as formas com que o Design pôde contribuir, por meio de um diálogo com a Educação, ao participar da ressignificação dos espaços de pré-escolas de São Tomé e Príncipe. A tarefa em si trouxe uma complexidade que requereu uma gama de conhecimentos e saberes, diante do ambiente construído para uso em uma infinidade de atividades, sendo habitado e vivenciado por crianças, educadores e demais usuários da escola, atendendo as necessidades materiais, éticas, estéticas, afetivas, diante da tarefa de desenvolvimento humano.

A descrição deste trabalho nos fez refletir sobre o desafio diante da adoção do enfoque metodológico do Design em Parceria, quando trabalhamos numa dimensão de diálogo e sutileza, em relação ao nosso parceiro de projeto, ao designarmos métodos e posturas que têm por finalidade alcançar a proximidade necessária com a comunidade usuária.

Essa foi a concepção que adotamos ao pensar o espaço da escola como um espaço comprometido por uma proposição mais justa na construção de um projeto educativo. No caso de São Tomé e Príncipe, foi vital pensar as ações com os educadores, apoiando experiências e conhecimentos de diferentes naturezas - emergindo, dessa forma, o potencial educador do Design junto aos espaços e tempos da Educação.

\section{Referências}

COUTO, M. Pensamentos: textos de opinião. 2.ed., Lisboa, Editorial Caminho, 2005.

COUTO, R. Movimento interdisciplinar de designers brasileiros em busca de educação avançada. 246 f. Tese (Doutorado em Educação) - Pontifícia Universidade Católica do Rio de Janeiro, Rio de Janeiro,1997.

O ensino da disciplina de Projeto Básico sob o enfoque do Design Social. Dissertação (Mestrado em Educação) - Departamento de Educação, PUC - Rio, Rio de Janeiro, 1991.

FONTOURA, A. M. A interdisciplinaridade e o ensino do design. Revista Projética. Universidade Estadual de londrina - UEL. Londrina, 2011.

FREIRE, M. Espaço e vida. In: MORAIS, Regis de (Org.). Sala de aula: que espaço é esse? Campinas: Papirus, 2004.

JORDY, E. A cartografia de espaços de educação para crianças pequenas sob o olhar do Design. 126 f. Tese (Doutorado em Artes e Design) - Pontifícia Universidade Católica do Rio de Janeiro, Rio de Janeiro, 2017.

. Design na ressignificação de espaços educativos em África. In: Revista D.: Design,

Educação, Sociedade e Sustentabilidade. v. 10, n. 1, 2018. Disponível em $<$ https://seer.uniritter.edu.br/index.php?journal=revistadesign\&page=article\&op=view\&path\% 5B\%5D=1622> Acesso em: 13 de março de 2018.

KOWALTOWSKI, D. Arquitetura escolar: o projeto do ambiente de ensino. 1. ed. São Paulo, SP: Oficina de Textos, 2012.

MORAES, K. Padrões mínimos de funcionamento da escola do ensino fundamental: ambiente físico escolar: guia de consulta. Fundescola/DIPRO/FNDE/MEC, Brasília. 2006 